\title{
Study on the Deformation of Pavement Structure with Multiplex Organic Hydraulicity Mixture under Driving Load Based on Simulation and Experiment
}

\author{
Hairong Gu, ${ }^{1}$ Lingying Zhao, ${ }^{1}$ Min Ye $\mathbb{D}^{1},{ }^{1}$ Zhiyong $\mathrm{Li},{ }^{1}$ Xinxin Xu, ${ }^{1,2}$ and Xianbao Zuo ${ }^{2}$ \\ ${ }^{1}$ National Engineering Laboratory for Highway Maintenance Equipment, Chang'an University, Xi'an 710064, China \\ ${ }^{2}$ Henan Gaoyuan Maintenance Technology of Highway Co.,Ltd., Xinxiang 453003, China \\ Correspondence should be addressed to Min Ye; mingye@chd.edu.cn
}

Received 14 April 2021; Accepted 13 September 2021; Published 11 October 2021

Academic Editor: Mara Criado

Copyright (c) 2021 Hairong Gu et al. This is an open access article distributed under the Creative Commons Attribution License, which permits unrestricted use, distribution, and reproduction in any medium, provided the original work is properly cited.

With the continuous growth of global warming and traffic volume, rutting deformation is common on road surfaces. A new type of pavement mixture, a semiflexible mixture, was proposed to solve the easy deformation and low riding quality of traditional pavement mixtures. It can be divided into pouring type and mixing type according to the construction method. However, there is little research on mixed semiflexible mixtures (i.e., multiplex organic hydraulicity $(\mathrm{MOH})$ mixtures) in the current literature, so the deformation of pavement under driving loads was studied based on the $\mathrm{MOH}$ mixture in this paper. Four types of pavement composed of the traditional mixture and $\mathrm{MOH}$ mixture (i.e., AC13-AC20, AC13-MOH, MOH-MOH, and MOH-AC20) were selected to achieve the purpose of the research. Based on these four types of pavement, the deformation of the pavement was studied by simulations and experiments. The results show that the deformation of the upper layer is almost the same for these four types of pavement and that the deformation of the middle layer changes substantially for these four types of pavement. In regard to the deformation, the relationship is $\mathrm{MOH}-\mathrm{MOH}<\mathrm{AC} 13-\mathrm{MOH}<\mathrm{MOH}-\mathrm{AC} 20<\mathrm{AC} 13-\mathrm{AC} 20$. In addition, the contribution rate of the deformation of the middle layer is much greater than that of the upper layer. The antideforming ability of the whole pavement can be improved by using the $\mathrm{MOH}$ mixture as the middle layer of the pavement, which means that the performance of the $\mathrm{MOH}$ mixture can achieve the best performance when it is applied to the middle layer.

\section{Introduction}

With the continuous growth of global warming and traffic volume, pavement damage is common on road surfaces, especially the rutting deformation of pavement, as shown in Figure 1 [1]. A new type of pavement mixture was proposed to solve the easy deformation and low riding quality of traditional pavement mixtures. This new mixture not only has the flexibility of asphalt mixtures but also has the rigidity of cement mixtures, so it is called a semiflexible mixture or semirigid mixture [2]. The semiflexible mixture is divided into pouring type and mixing type according to the construction method [3]. The former is a combination of hot mixing and cold pouring, the process is complex, and the construction quality is challenging to control. However, the mixed semiflexible mixture is a kind of $\mathrm{MOH}$ mixture with an emulsified asphalt cement mixture as binder $[4,5]$. This can realize typical temperature construction, especially in alpine regions [5]. The mixed semiflexible mixtures have been of great interest to highway experts worldwide in recent years because of its convenient construction, energy consumption reduction, and environmental protection. According to the literature, the energy consumption and carbon emissions of $\mathrm{MOH}$ mixtures in the construction period were $81.60 \mathrm{MJ} / t$ and $6.05 \mathrm{~kg} / t$, respectively, $71.20 \%$ lower than those of traditional asphalt pavement [6].

Research on emulsified asphalt cement mortar mixtures mainly focuses on the mixing ratio $[7,8]$, performance $[5,9-14]$, mixing time [15], strength formation mechanism $[7,16,17]$, and so on. For pavement materials, understanding their performance is the priority. Gong et al. studied the cracking resistance of semiflexible mixtures, and 


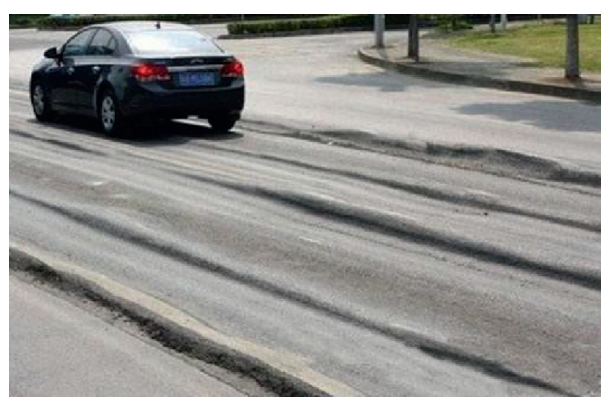

FIgURE 1: Rutting damage of pavement.

the results showed that mixtures using modified asphalt binders and fibres had fewer cracks [18]. Liu et al. studied the effect of binders on the properties of mixtures. The results showed that the influence of cement and emulsified asphalt on the properties (tensile and compressive strength) was nonlinear and that the optimal amounts of emulsified asphalt and cement were determined to be $2.9 \%$ and $1.5 \%$ for the recycled materials, respectively $[16,19]$. Jahanbakhsh et al. examined the fatigue cracking resistance behaviour of cement emulsified asphalt mortar, and the most suitable parameter for evaluating the fatigue cracking resistance was specified [20]. Moghadas et al. considered the mechanical and fatigue properties of cement emulsified asphalt mortar; the results showed that both uniaxial compressive strength and indirect tensile strength heightened through the inclusion of silica fume [21]. Zhang et al. studied the viscosity of emulsified asphalt cement mortar. It was concluded that the structure of cement hydrates not only improved the consistency of the slurry but also contributed to the optimization of the adhesion and film-forming effect of emulsified asphalt [22].

Methods for exerting the best performance (i.e., rutting resistance) of the pavement mixture are worthy of attention and research. At present, asphalt pavement composed of a bottom layer, middle layer, and upper layer [23] has been substantially studied. For example, Li et al. studied the high-temperature performance of two kinds of doublelayer asphalt pavements composed of AC-13, AC-20, and SMA-13 mixtures using fractal dimensions based on fractal theory; the result showed that the deformation is divided into two stages (i.e., densification and flow deformation), ant that the top layer made of AC-13 presented obvious densification [24]. Hu et al. analysed the rutting performance of three-layer asphalt pavement composed of AC25, AC-20, and SMA-13 under the temperature field using the finite element software ABAQUS. The result showed that the contribution rate of each layer to the total deformation of the pavement was different; that is, the middle layer was the largest, the bottom layer was the lowest, and the upper layer was the smallest [25]. Hu et al. studied the deformation of the asphalt concrete (AC) layer of pavement with different variables using the finite element method, such as the AC layer modulus, AC layer thickness, vertical wheel loads, and tire pressure. The result showed that the permanent deformation (PD) contribution of each $\mathrm{AC}$ layer varies as a function of the AC modulus and the distribution of the tire pressure has a very significant influence on the PD of the top AC layer [26]. Jiang et al. studied the influence of materials (i.e., AC-16, AC-20, AC25 , and AC-13) and the thickness of double-layer asphalt pavement on the high-temperature performance, and a double-layer pavement structure with a $3 \mathrm{~cm}$ AC- 16 surface layer and a $7 \mathrm{~cm}$ AC-20 bottom layer was recommended [27]. Jiang et al. proposed an inverted asphalt pavement structure $(4 \mathrm{~cm}$ AC-13 mixture $+8 \mathrm{~cm}$ AC-25 mixtur$\mathrm{e}+6 \mathrm{~cm}$ AC-20 mixture $+54 \mathrm{~cm}$ cement-stabilized macadam), and the result showed that it had better rutting resistance than the traditional asphalt pavement structure ( $4 \mathrm{~cm} \mathrm{AC-13} \mathrm{mixture}+6 \mathrm{~cm}$ AC-20 mixture $+8 \mathrm{~cm} \mathrm{AC-25}$ mixture $+54 \mathrm{~cm}$ cement-stabilized macadam) [28].

Based on the above analysis, it can be found that the performance of the whole pavement is rarely studied when the $\mathrm{MOH}$ mixture is applied to the pavement. To compensate for this research gap, the deformation of pavement under driving loads was studied based on the $\mathrm{MOH}$ mixture in this paper. Four types of pavement composed of $\mathrm{MOH}$ mixtures and conventional mixtures (i.e., AC13-AC20, $\mathrm{AC} 13-\mathrm{MOH}, \mathrm{MOH}-\mathrm{MOH}$, and $\mathrm{MOH}-\mathrm{AC} 20$ ) are taken as research objects. Here, AC13-AC20 is a type of pavement structure in which the upper layer adopts an AC-13 mixture and the middle layer adopts an AC-20 mixture. The other types have the same meaning. Based on these four types of pavement, the deformation of the pavement was studied by simulations and experiments.

\section{Theory of Permanent Deformation of Pavement}

The road structure is usually composed of a surface layer, base course, subbase, and subgrade, and the surface layer includes an upper layer, middle layer, and lower layer. Pavement deformation usually occurs in the surface layer. The calculation of the permanent deformation is usually based on the maximum vertical compressive stress of the top of each layer in the surface layer; namely [29],

$$
\left\{\begin{array}{l}
R_{a}=\sum_{i=1}^{n} R_{\mathrm{ai}} \\
R_{\mathrm{ai}}=2.31 \times 10^{-8} k_{\mathrm{Ri}} T_{\text {pef }}^{2.93} p_{i}^{1.80} N_{e 3}^{0.48} \frac{h_{i}}{h_{0}} R_{0 i}
\end{array},\right.
$$


where $R_{\mathrm{a}}$ and $R_{\mathrm{ai}}$ are the permanent deformations of the surface layer and each layer in the surface layer, respectively. $N$ is the number of layers in the surface layer. $T_{\text {pef }}$ is the equivalent temperature of the permanent deformation. $N_{\mathrm{e} 3}$ is the cumulative number of applied loads. $h_{\mathrm{i}}$ is the thickness of the ith layer in the surface layer. $h_{0}$ is the thickness of the rutting test specimen. $\mathrm{R}_{0 \mathrm{i}}$ is the permanent rutting deformation of the ith layer at $60^{\circ} \mathrm{C}, 0.7 \mathrm{MPa}$, and loading of 2520 cycles. $k_{\mathrm{Ri}}$ is the comprehensive correction coefficient, and its calculation formula is shown in equation (3). $p_{\mathrm{i}}$ is the vertical compressive stress on the top of the $i$ th layer; namely [29],

$$
\left\{\begin{array}{l}
p_{i}=p \bar{p}_{i}, \\
\bar{p}_{i}=f\left(\frac{h_{1}}{\delta}, \frac{h_{2}}{\delta}, \ldots \frac{h_{n-1}}{\delta} ; \frac{E_{2}}{E_{1}}, \frac{E_{3}}{E_{2}}, \ldots, \frac{E_{0}}{E_{n-1}}\right)
\end{array}\right.
$$

where $\bar{p}_{i}$ is the theoretical compressive stress coefficient. $p$ and $\delta$ are the wheel pressure and equivalent radius of the standard axle load, respectively. $h_{\mathrm{i}}$ and $E_{\mathrm{i}}$ are the thickness and resilient modulus of each layer in the pavement structure, respectively. $E_{0}$ is the resilient modulus of the subgrade.

The comprehensive correction coefficient can be expressed as follows [29]:

$$
\left\{\begin{array}{l}
k_{R i}=0.9731^{z_{i}}\left(d_{1}+d_{2} \cdot z_{i}\right) \\
d_{1}=-1.35 \times 10^{-4} h_{a}^{2}+8.18 \times 10^{-2} h_{a}-14.5 \\
d_{2}=8.78 \times 10^{-7} h_{a}^{2}-1.5 \times 10^{-3} h_{a}+0.9
\end{array}\right.
$$

where $z_{\mathrm{i}}$ is the depth of the $i$ th layer and $h_{\mathrm{a}}$ is the thickness of the surface layer.

\section{Simulation Analysis Based on Pavement Deformation}

To obtain the maximum vertical compressive stress of each layer in the surface layer and to study the deformation of the $\mathrm{MOH}$ mixture applied to pavement, a numerical simulation based on the pavement was carried out. In this study, different mixtures were selected and applied to the surface layer to form a contrast.

\subsection{Numerical Simulation Setup}

3.1.1. Road Structure and Parameters. The pavement structure composed of the surface layer (upper layer, middle layer, and lower layer), base, subbase, and subgrade was selected. The materials and parameters of each layer of pavement are shown in Table 1 . The rebound moduli were all references [30-34]. Four different pavement structure combinations were designed, as shown in Figure 2. Because the materials used in other layers were consistent, only the upper layer and middle layer of the pavement surface layer are drawn in Figure 2.
3.1.2. Finite Element Model. Based on the above road structure, ABAQUS software was used to establish the threedimensional finite element model of the road. The model size was $6 \mathrm{~m} \times 6 \mathrm{~m} \times 3 \mathrm{~m}$ (length $\times$ width $\times$ height). The following assumptions are made for the pavement to reduce the simulation time. (1) Each layer is uniform, continuous, and isotropic in the pavement structure. (2) The gravity and unevenness of the road are ignored. (3) The connection between the layers is entirely continuous.

Because both the side and bottom of the pavement were limited to a certain extent, the boundary conditions of the pavement model were set; that is, the bottom surface was fully constrained, and the lateral displacement of the side in two horizontal directions was limited.

A load area of $0.8 \mathrm{~m} \times 0.6 \mathrm{~m}$ was set at the top of the model to simulate the wheel load [35]. The standard axle load BZZ-100 was adopted [36]. The load was simplified to a $0.23 \mathrm{~m} \times 0.16 \mathrm{~m}$ uniform rectangular load to facilitate grid division. The detailed layout of the loading is shown in Figure 3.

Before the simulation starts, the model needed to be mesh. To save simulation time and improve the calculation accuracy, the meshing in the load area was fine, and the part far away from the load area was rough. The mesh of the model is shown in Figure 4.

\subsection{Simulation Results and Discussion Based on Deformation}

3.2.1. Vertical Strain on Top of the Subgrade. The vertical strain at the top of the subgrade is shown in Figure 5. Because one pavement structure type is used in this study, only the strain of the combined type AC13-MOH is shown in Figure 5(a). See Figure S1 in Supplementary Materials for the strain diagrams of the other combination types. In Figure 5(a), $X$ and $Y$ represent the distance from the centre of the two wheels, where $X$ represents the distance in the driving direction and $\mathrm{Y}$ represents the distance on the cross section of the road. This meaning can be applied to other figures in this study. Figure 5(a) shows that the strain value of the top of the subgrade gradually decreases with increasing distance from the centre of the two wheels. To intuitively express the relationship between the four combination types, Figure 5(b) shows the strain at the top of the subgrade at $X=0$. Figure $5(\mathrm{~b})$ shows that the strain value of AC13-AC20 under loading is larger than that of $\mathrm{MOH}$ $\mathrm{MOH}$, which indicates that $\mathrm{AC} 13-\mathrm{AC} 20$ is prone to permanent deformation compared with $\mathrm{MOH}-\mathrm{MOH}$.

3.2.2. Instantaneous Vertical Displacement. Figure 6 shows the instantaneous vertical displacement of each layer of four different types of pavement combinations, and the units of the value on the contour line are in $\mathrm{mm}$. Figure 6 shows that the vertical displacement is less likely to occur farther away from the road surface. The vertical displacements of the $\mathrm{AC} 13-\mathrm{MOH}$ and $\mathrm{MOH}-\mathrm{AC} 20$ structures are almost equal in each layer. The displacement of AC13-AC20 is greater than that of $\mathrm{MOH}-\mathrm{MOH}$. Additionally, it can be found that the instantaneous vertical displacement of AC13-AC20 is 
TABLE 1: Pavement structure materials and parameters.

\begin{tabular}{lcccc}
\hline \multicolumn{2}{c}{ Pavement structure layer } & Thickness $(\mathrm{cm})$ & Resilient modulus (MPa) & Poisson's ratio \\
\hline \multirow{2}{*}{ Upper layer } & AC-13 & 4 & 1400 & 1600 \\
& MMOH & & 2000 & 0.35 \\
\hline \multirow{2}{*}{ Middle layer } & AC-20 & 6 & 2400 & 0.35 \\
& CMOH & & 3500 & 0.35 \\
Lower layer & AC-25 & 8 & 1200 & 0.2 \\
Base & CTB & 40 & 300 & 0.3 \\
Subbase & CTB & 25 & 45 & 0.4 \\
Subgrade & SG & - & & \\
\hline
\end{tabular}

AC: asphalt concrete; $\mathrm{MMOH}$ : medium-grained $\mathrm{MOH}$ mixture; $\mathrm{CMOH}$ : coarse-grained $\mathrm{MOH}$ mixture; CTB: cement-treated macadam base; SG: subgrade.

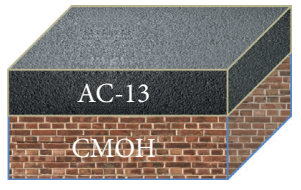

(a)

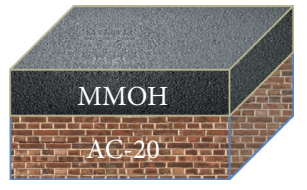

(b)

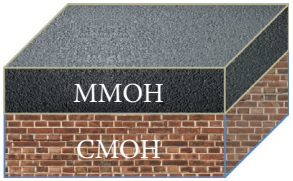

(c)

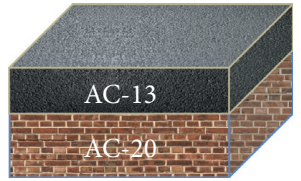

(d)

Figure 2: Combination types of pavement structures. (a) Type 1. (b) Type 2. (c) Type 3. (d) Type 4.

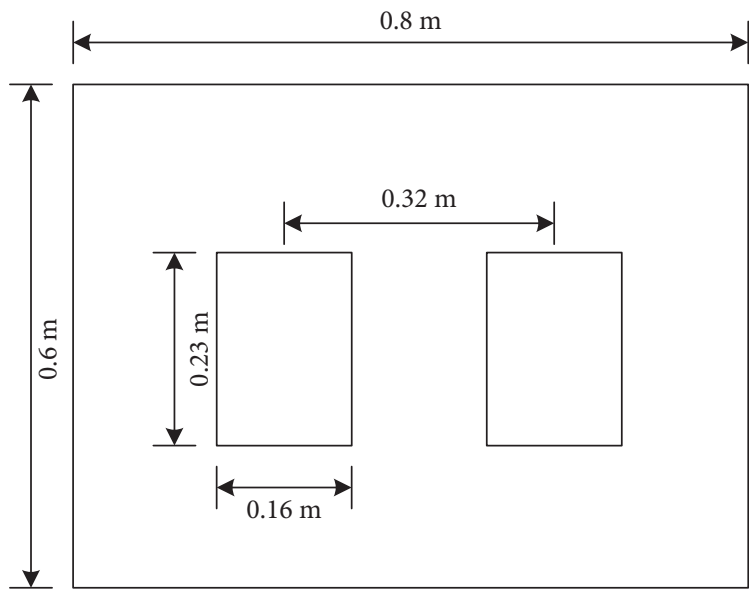

FIgURE 3: Layout of rectangular loading.

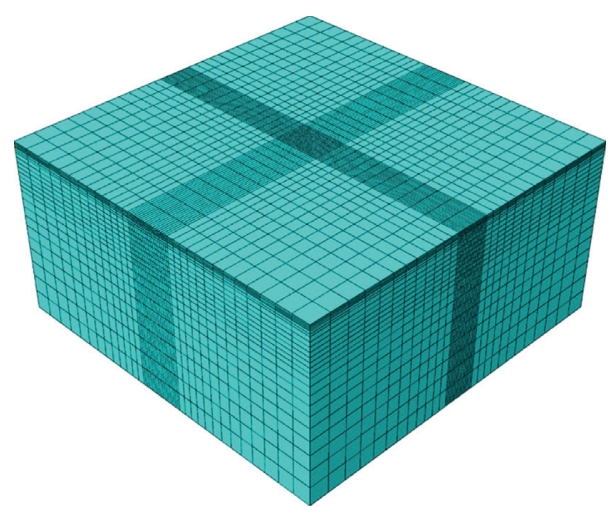

FIGURE 4: Meshing of the finite element model.

different from other types of combinations at the centre of the two wheels. This may be due to the weak resistance of the AC13-AC20 structure to external forces. When the wheel runs on the pavement, the pavement contacting with the wheel will deform instantaneously to resist the external force, and the force extending to the centre of the two wheels 


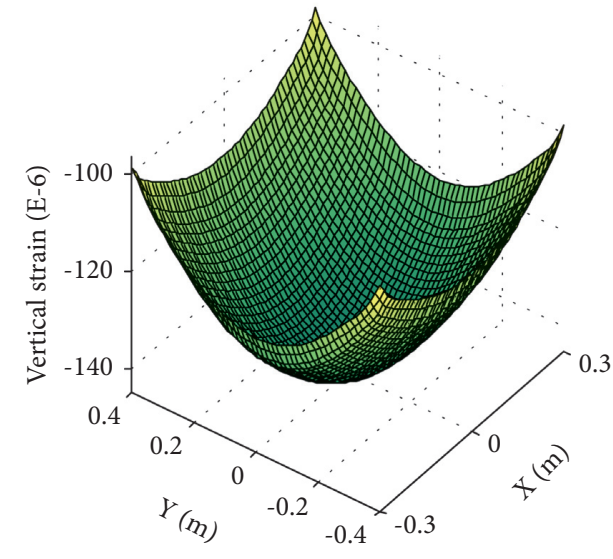

(a)

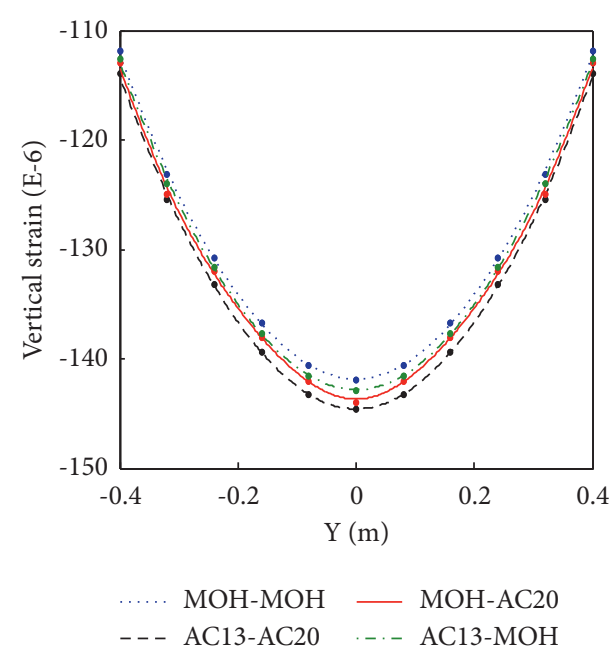

(b)

Figure 5: Vertical strain on top of the subgrade. (a) AC13-MOH. (b) $X=0$.

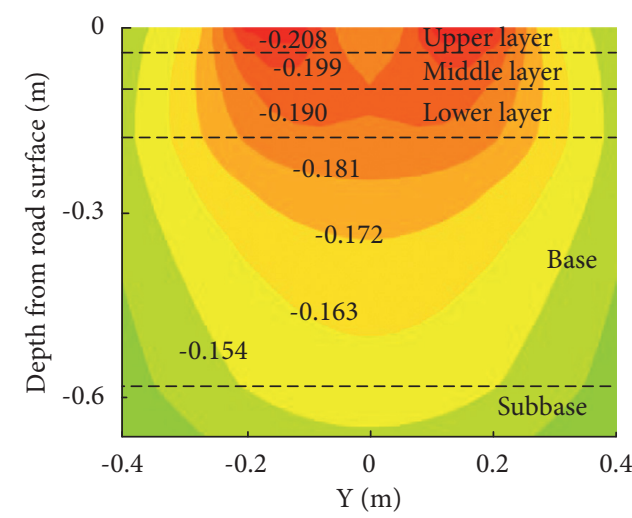

(a)

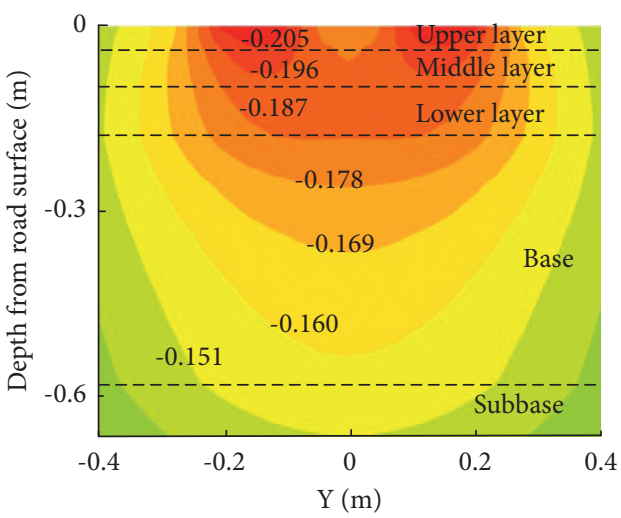

(c)

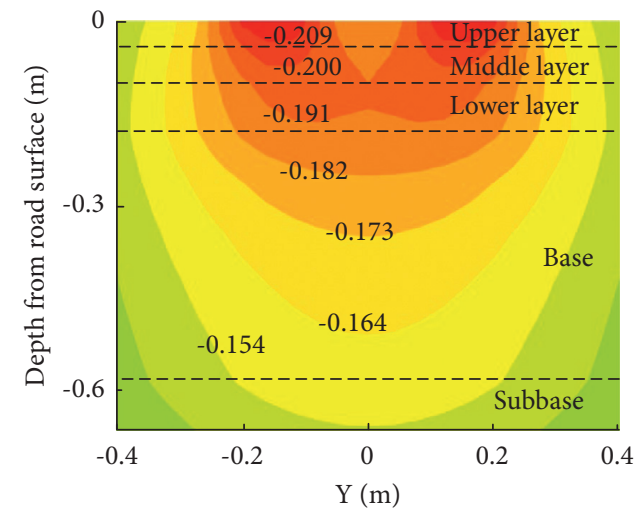

(b)

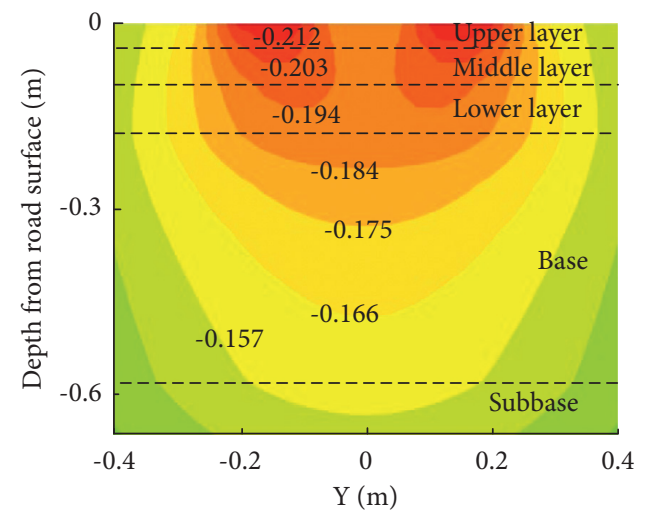

(d)

Figure 6: Contours of instantaneous vertical displacement. (a) AC13-MOH. (b) MOH-AC20. (c) MOH-MOH. (d) AC13-AC20.

is smaller. Therefore, the deformation of the AC13-AC20 structure has no area with the same degree of deformation as that of the roller surface at the centre of the two wheels.

To more intuitively display the vertical deformation of the pavement, the instantaneous vertical displacement of the pavement surface at $X=0$ is shown in Figure 7. In Figure 7, it can be found that the road surface near the wheel subsides to different degrees under the action of loading and the place near the centre of the two wheels is raised upward. Thus, a letter $\mathrm{W}$ is formed on the road surface. Combined with Figures 6 and 7, it can be concluded that the relationship between the four combination types from the vertical 


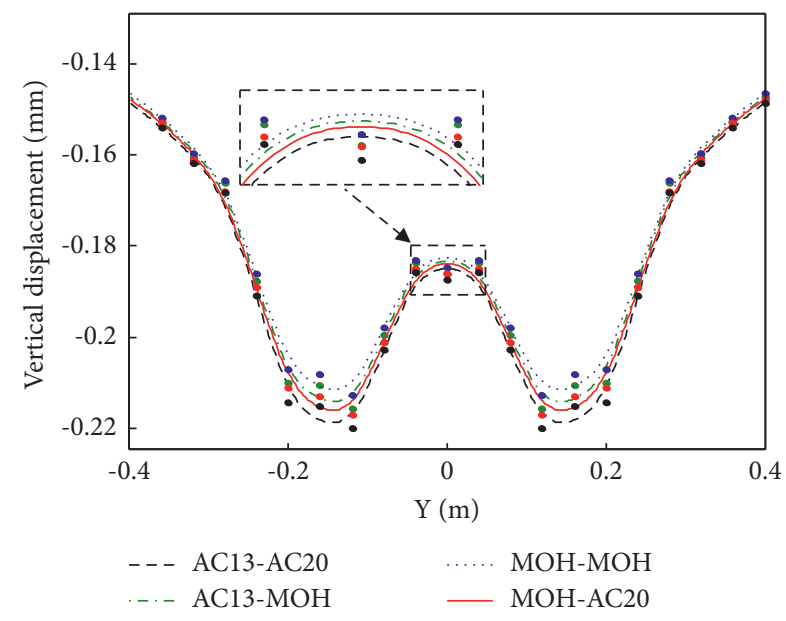

FIGURE 7: Instantaneous vertical displacement of the road surface at $X=0$.

displacement is as follows: $\mathrm{MOH}-\mathrm{MOH}<\mathrm{AC13}-\mathrm{MOH}<$ $\mathrm{MOH}-\mathrm{AC} 20<\mathrm{AC} 13-\mathrm{AC} 20$.

3.2.3. Vertical Stress and Permanent Deformation in the Surface Layer. From equation (1), it can be seen that the value of parameter pi is needed in the calculation of the pavement surface layer deformation. The surface layer is layered. In this study, the upper layer was divided into two layers, the middle layer was divided into three layers, and the lower layer was divided into two layers. Based on this layer and the simulation results, the vertical stress at the top of each layer can be obtained. Then, the permanent deformation of the surface layer can be obtained.

Figure 8 shows the vertical stress distribution of the pavement. Because one pavement structure type is used in this study, only the stress of the combined type $\mathrm{MOH}-\mathrm{MOH}$ is shown in Figure 8(a). See Figure S2 in Supplementary Materials for the stress diagrams of other combination types. In Figure 8(a), the units of the values displayed in the contours are $\mathrm{kPa}$, and a negative sign indicates that the stress is compressive. Figure 8(a) shows that the vertical stress decreases with increasing depth from the road surface. The upper and middle layers bear most of the stress. Therefore, the deformation resistance of the upper and middle layers should be considered. The maximum stress of each layer in the surface layer is shown in Figure 8(b). As shown in Figure 8(b), the stress value of the corresponding layers of each combination type has little difference. Compared with other layers, the middle layer has a considerable change rate of stress.

According to equation (1) and Figure 8(b), the deformation of the surface layer can be obtained. To correspond with the experimental results, the deformation results of the pavement under $10^{5}$ load cycles are calculated, as shown in Table 2. As shown in Table 2, when the AC-13 mixture and $\mathrm{MOH}$ mixture are used in the upper layer, the deformation of the upper layer is almost the same. However, when the $\mathrm{MOH}$ mixture and AC-20 mixture are selected as the middle layer, the deformation of the middle layer changes substantially, which means that the key to improving the antideforming ability of the pavement is the middle layer. The total deformations of the AC13-AC20 and MOH-AC20 surface layers are larger than those of $\mathrm{AC} 13-\mathrm{MOH}$ and $\mathrm{MOH}-\mathrm{MOH}$.

\section{Experiments Based on the Pavement Surface Layer}

\subsection{Experimental Setup}

4.1.1. Experiment Instruments. A vertical loaded circle-road test was applied, which can simulate the road stress conditions. The structure of the device is shown in Figure 9. The deformation of pavement under driving loads can be quickly obtained by using the device. As shown in Figure 9(a), the equipment is composed of a chamber, instrument panel, and running mechanism that drives the road to rotate, a loading application mechanism that applies wheel loads to the specimen, and a thermostatic mechanism that controls the temperature in the chamber. The up and down movement of the hydraulic cylinder in Figure 9(b) is adjusted by turning the hand wheel on the instrument panel. At this time, the wheel pressure is displayed on the instrument panel through the pressure sensor in the sensor shaft to realize the adjustment of wheel pressure. The speed controller on the instrument panel can realize the movement of the rotating road through the transmission and power mechanism. The temperature in the chamber is controlled by the temperature controller, which can realize the heating or stopping of the air flowing through the heating furnace.

In this device, the road is moving relative to the wheel. The specimen was fixed to the rotary road with threaded fasteners through the holes, as shown in Figure 9(b). Through the repeated rotation of the rotary road, the surface of the specimen was deformed under the action of wheel pressure, and then the purpose of the experiment was realized. During the test, the working conditions of the tester shown in Figure 9 were as follows. The load of the specimen was selected as the standard axle load BZZ-100; that is, the pressure of the wheelset specimen was $0.7 \mathrm{MPa}$ and the wheel load was $100 \mathrm{kN}$. Temperature and vehicle speed will affect the deformation of the road. In this experiment, the selected parameters are more extreme, that is, the summer road temperature and the slower driving speed. The test temperature was $60^{\circ} \mathrm{C}$. The running speed of the road was $10 \mathrm{~km} / \mathrm{h}$, the road was loaded with a fixed wheel rail, and there was no lateral movement.

4.1.2. Materials and Sample Preparation. Due to the limitation of the experimental conditions, only the upper and middle layers of the pavement surface structures were selected for the tests. The raw materials needed in this experiment were aggregates, cement, water, emulsified asphalt, mineral powder, and fibres The $\mathrm{MOH}$ mixture is composed of aggregates, cement, water, emulsified asphalt, and fibres [15], while the asphalt mixture is composed of aggregates, mineral powder, and asphalt [37]. The aggregates used in the 

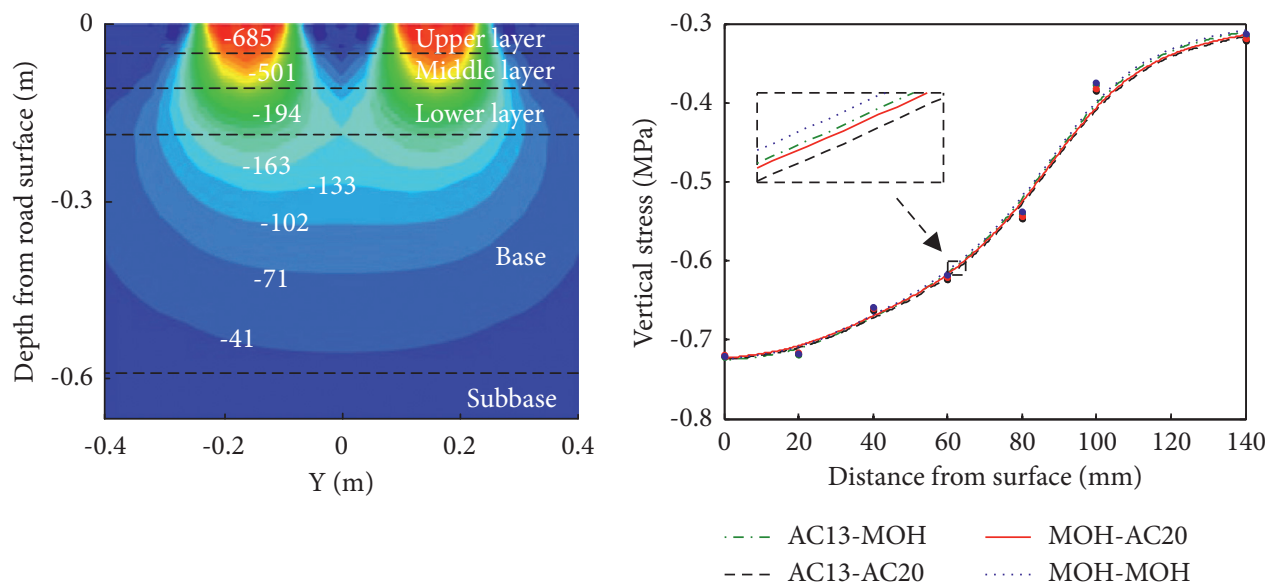

(a)

(b)

FIgURE 8: Vertical stress. (a) MOH-MOH. (b) Surface layer.

TABle 2: Deformation of the surface layer under $10^{5}$ load cycles.

\begin{tabular}{lccccc}
\hline Type & & AC13-MOH & MOH-AC20 & MOH-MOH & AC13-AC20 \\
\hline \multirow{3}{*}{ Deformation $(\mathrm{mm})$} & Upper & 2.03 & 2.02 & 2.02 & 2.03 \\
& Middle & 6.08 & 9.80 & 5.25 & 12.29 \\
& Surface & 9.56 & 13.89 & 8.30 & 16.75 \\
\hline
\end{tabular}

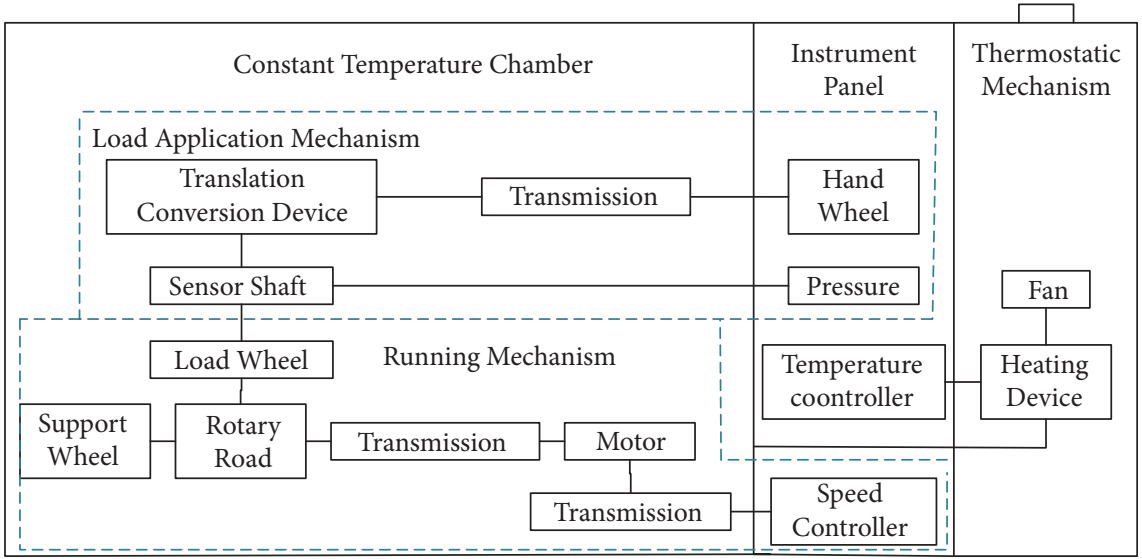

(a)

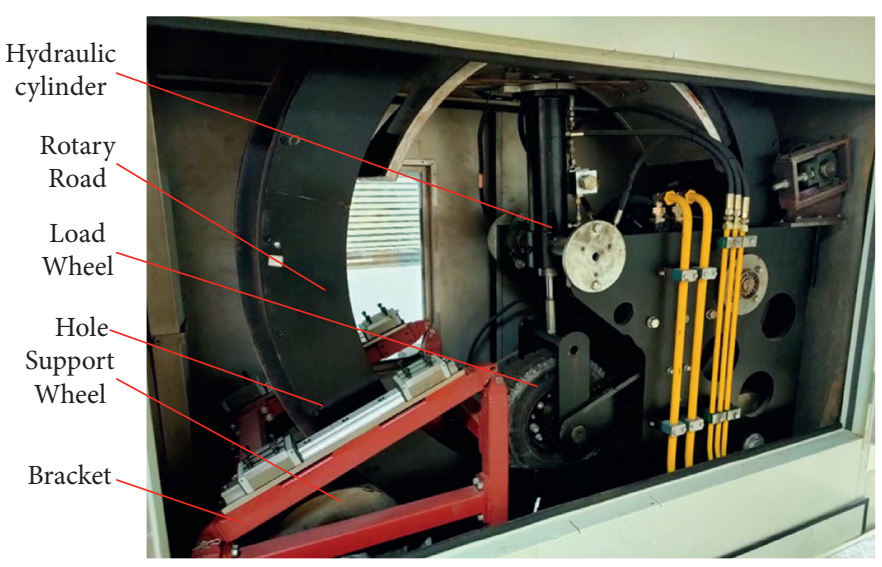

(b)

Figure 9: Vertical loaded circle-road tester. (a) Schematic diagram. (b) Actual diagram. 
test were basalt. The mineral powder was limestone powder. The emulsified asphalt used in the test was slow cationic cracking and fast setting emulsified asphalt. Portland cement with grade 42.5 was used, and the content was $1 \%$. The fibres were polypropylene fibres with $0.1 \%$ content. The water was tap water. The aggregate gradation and asphalt aggregate ratio of each type of mixture are shown in Table 3 and Figure 10. This oil-stone ratio was the best ratio determined by the Marshall method [38]. The main characteristics of the raw materials are shown in Table 4.

The production process of the specimen was to make the middle layer of the specimen first and then the upper layer. Before paving the upper layer, emulsified asphalt was applied to the surface of the middle layer to improve the adhesion between the two [24]. The specific operation process of specimen preparation can be referred to in the work in [24]. Because the final formed pavement specimen was installed on the tester for the experiment, special forming equipment for the test piece was applied to make the specimen fit the tester. Two specimens were made for each pavement structure to reduce the error of the results.

\subsection{Experiment Results and Discussion}

4.2.1. Image Processing and Results of the Specimen. The specimens were processed by image processing to intuitively observe the deformation of the pavement under loading. The processing method was as follows: (1) before the specimen was installed on the tester, a grid with a spacing of $1 \mathrm{~cm}$ was sprayed on the end face of the specimen. (2) After the grid spraying was completed, the image information of the cross section of the specimen before the test was collected. The relative position between the camera and each specimen should be unchanged. The distance between the camera and the test piece was $40 \mathrm{~cm}$ in this experiment. (3) After the test, the specimen was removed from the tester, and the image information of the cross section of the specimen was collected by the same method used before the test.

By comparing the images of the end face of the specimen before and after the test, the change in the specimen before and after the load can be intuitively observed, as shown in Figure 11. Figure 11 shows that MOH-AC20 and AC13AC20 have large deformations under loading times, while $\mathrm{AC} 13-\mathrm{MOH}$ and $\mathrm{MOH}-\mathrm{MOH}$ are relatively small under the same loading times. In addition, from the change in the grid line, the deformation of the pavement is three-dimensional under the action of the load; that is, it is not a simple oneway deformation but deformation in all directions.

4.2.2. Deformation Analysis of the Specimen. Figure 12 shows the deformation depth of each specimen under $10^{5}$ loading cycles. Figure 12 shows that the depth of AC13AC20 is the largest. When the upper layer of the pavement is an $\mathrm{AC}-13$ mixture or $\mathrm{MOH}$ mixture, the antideforming ability of the middle layer using the $\mathrm{MOH}$ mixture is better than that of the AC-20 mixture. When the middle layer is an $\mathrm{MOH}$ mixture, the upper layer can use the $\mathrm{MOH}$ mixture or AC-13 mixture. When the middle layer of the pavement is an
TABLE 3: Oil-stone ratio.

\begin{tabular}{lcccc}
\hline Type of mixture & AC-20 & AC-13 & CMOH & MMOH \\
\hline Oil-stone ratio (\%) & 4.2 & 4.7 & 5.4 & 6.0 \\
\hline
\end{tabular}

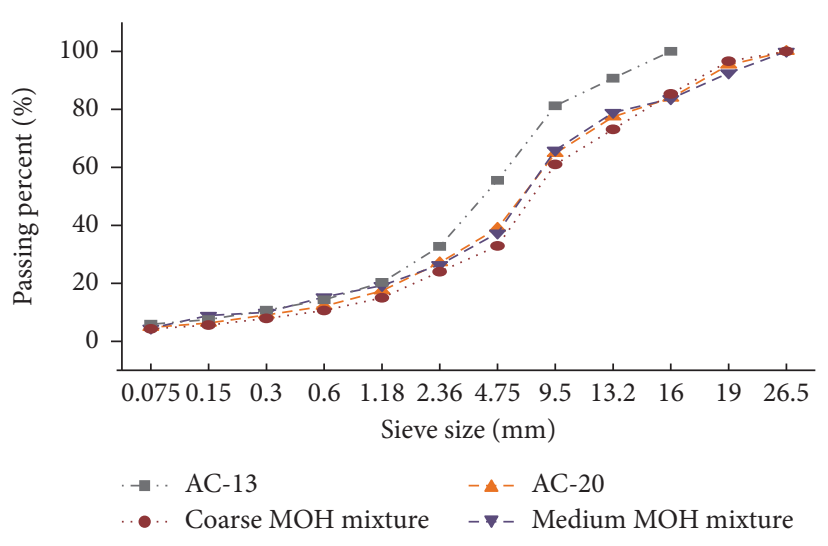

FIGURE 10: Gradation of each type of mixture.

Table 4: Properties of the raw materials.

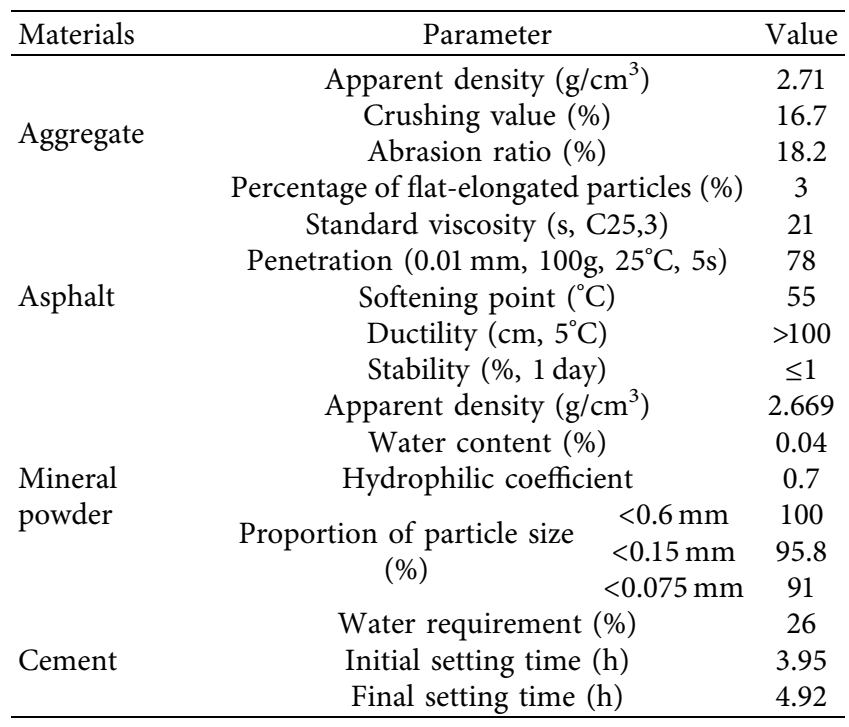

AC-20 mixture, the antideforming ability of the upper layer of the pavement with the $\mathrm{MOH}$ mixture is better than that of the AC-13 mixture.

The final deformation results were obtained by averaging the deformation values of the same structural specimens in the experiment. Then, the experimental results were compared with the simulation results. The specimen was composed of the middle layer and the upper layer, so the total deformation of the upper layer and the middle layer was compared, as shown in Table 5. The error was within a relatively reasonable range, which indicated the correctness of the simulation results.

4.2.3. Analysis of the Contribution Rate of Each Layer to the Total Deformation. To compare and analyse the effect of using the different mixtures in the middle and upper layers, 

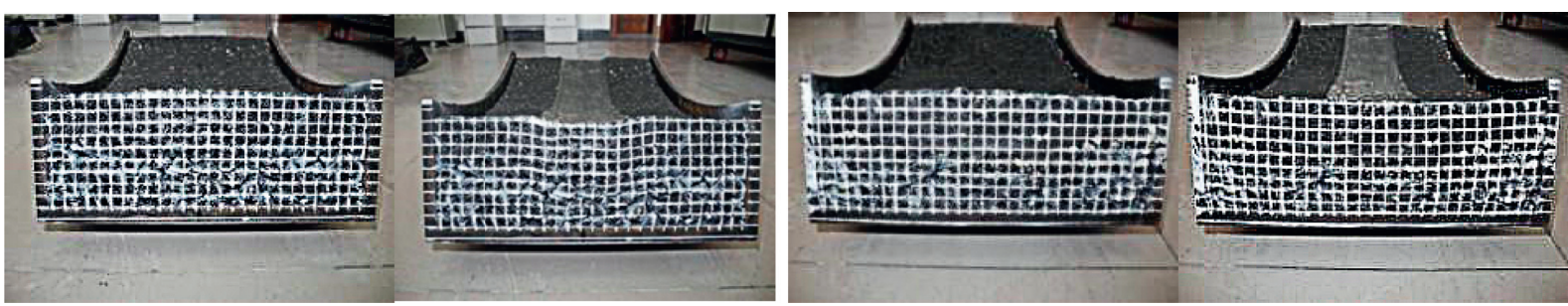

(a)
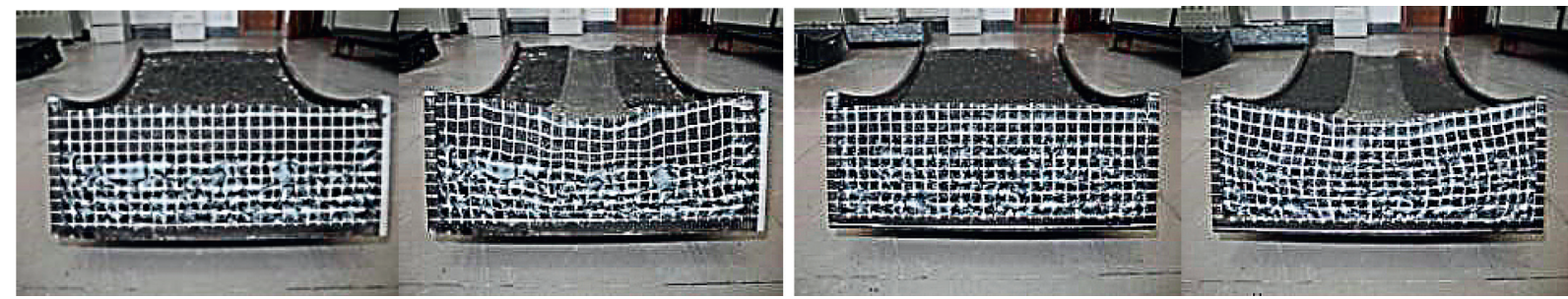

(b)
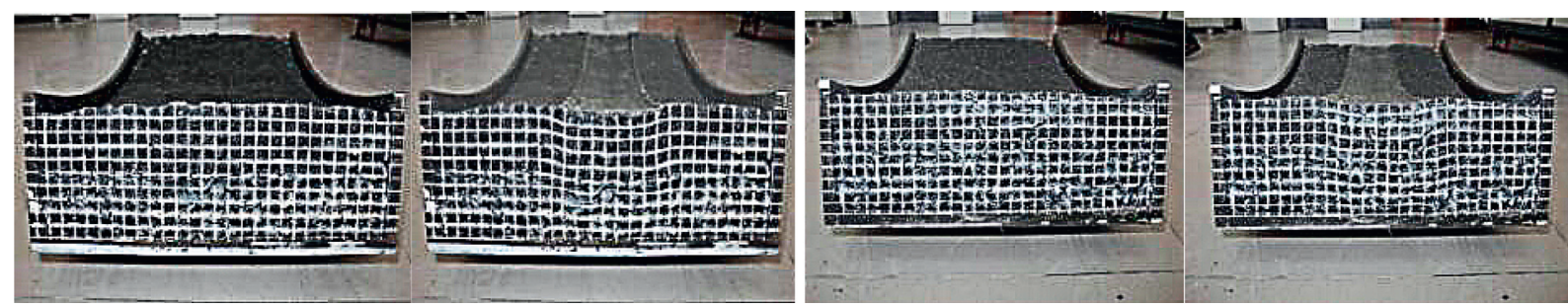

(c)
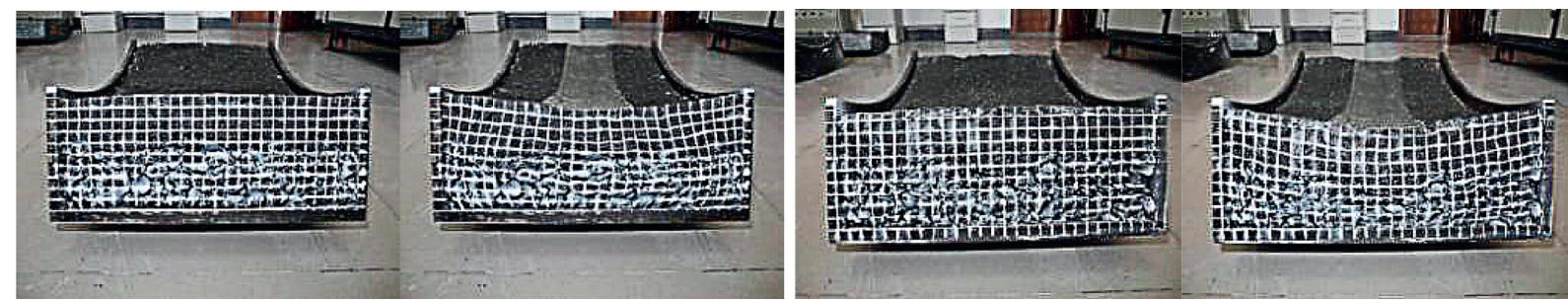

(d)

Figure 11: Comparison of the specimens before and after loading. (a) AC13-MOH. (b) MOH-AC20. (c) MOH-MOH. (d) AC13-AC20.

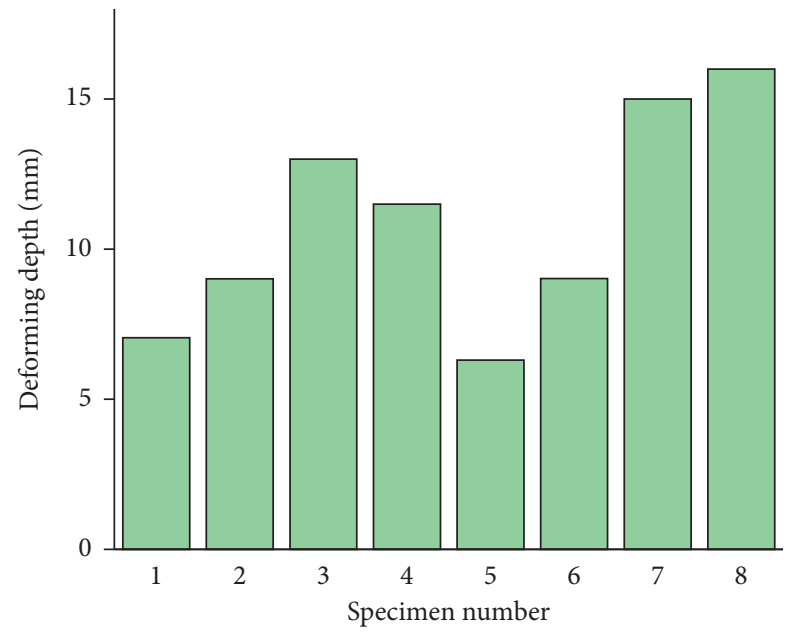

FIgure 12: Absolute deforming depth. The structure type of specimen numbers 1 and 2 is AC-13-MOH. The structure type of specimen numbers 3 and 4 is $\mathrm{MOH}-\mathrm{AC}-20$. The structure type of specimen numbers 5 and 6 is $\mathrm{MOH}-\mathrm{MOH}$. The structure type of specimen numbers 7 and 8 is AC13-AC20. 
TABLE 5: Error between the experimental and simulation results.

\begin{tabular}{lcccc}
\hline Type & AC13-MOH (\%) & MOH-AC20 (\%) & MOH-MOH (\%) & AC13-AC20 (\%) \\
\hline Relative error & 1.1 & 3.7 & 5.4 & 8.3 \\
\hline
\end{tabular}

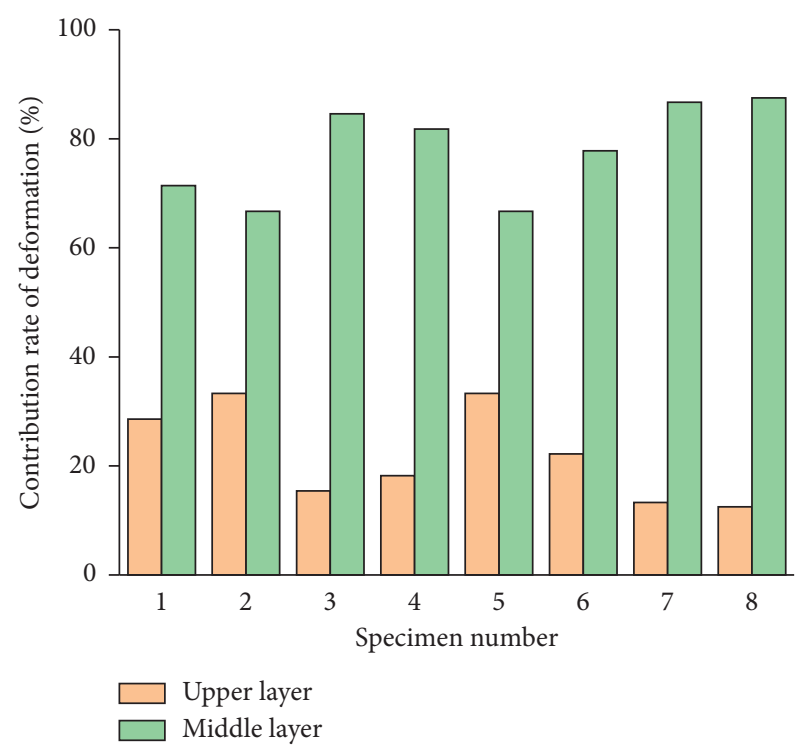

FIGURE 13: Deformation contribution rate of each layer for the specimens. The structure type of specimen numbers 1 and 2 is AC13-MOH. The structure type of specimen numbers 3 and 4 is $\mathrm{MOH}-\mathrm{AC}-20$. The structure type of specimen numbers 5 and 6 is $\mathrm{MOH}-\mathrm{MOH}$. The structure type of specimen numbers 7 and 8 is AC13-AC20.

TABLE 6: Deformation contribution rate of each layer for different pavement structures.

\begin{tabular}{lccc}
\hline \multicolumn{2}{c}{ Pavement structure type } & \multicolumn{2}{c}{$\begin{array}{c}\text { Contribution rate of } \\
\text { deformation (\%) }\end{array}$} \\
Upper layer & Middle layer & Upper layer & Middle layer \\
\hline AC-13 & MOH & 31.0 & 69.0 \\
MOH & AC-20 & 16.8 & 83.2 \\
MOH & MOH & 27.8 & 72.2 \\
AC-13 & AC-20 & 12.9 & 87.1 \\
\hline
\end{tabular}

the contribution rate of the deformation in different layers was analysed. The proportion of the upper and middle layer deformation in the total deformation was obtained by measuring the thickness changes of each layer before and after loading, as shown in Figure 13. The deformation contribution rates of the upper and middle layers under different structure types can be obtained by averaging the test data of specimens with the same structure, as shown in Table 6. It can be seen from Figure 13 and Table 6 that the deformation contribution rate of the middle surface layer is far greater than that of the upper layer, so the antideformation of the middle layer should be considered. The antideforming ability of the $\mathrm{MOH}$ mixture is better than that of the AC-20 mixture, so the antideforming ability of the whole pavement structure can be improved by using the $\mathrm{MOH}$ mixture in the middle layer.

\section{Conclusions}

Based on the MOH mixture, the deformation of different pavement structures under the driving load is studied. The following conclusions are drawn:

(1) In regard to the vertical strain and instantaneous vertical displacement at the top of the subgrade, the relationship between the four types of pavement is as follows: $\quad \mathrm{MOH}-\mathrm{MOH}<\mathrm{AC13}-\mathrm{MOH}<\mathrm{MOH}-$ AC20 $<$ AC13-AC20, which indicates that AC13AC20 is prone to permanent deformation.

(2) The vertical stresses of the corresponding layers for each combination type exhibit few differences, but the middle layer has the most extensive change rate of stress compared with the upper layer and lower layer.

(3) For these four types of pavement, the deformation of the upper layer is almost the same, and the deformation of the middle layer changes substantially.

(4) The results of pavement deformation under $10^{5}$ load cycles show that the deformations of AC13-AC20 and $\mathrm{MOH}-\mathrm{AC} 20$ are larger than those of $\mathrm{AC13}$ $\mathrm{MOH}$ and $\mathrm{MOH}-\mathrm{MOH}$.

(5) The contribution rate of the deformation of the middle layer is much greater than that of the upper layer. The $\mathrm{MOH}$ mixture used in the middle layer can improve the antideformation ability of the whole pavement structure.

\section{Data Availability}

The data used to support the findings of this study are included within the article.

\section{Conflicts of Interest}

The authors declare that there are no conflicts of interest regarding the publication of this article.

\section{Acknowledgments}

This work was supported by the National Science and Technology Support Program under Grant 2015BAF07B08, National Key R\&D Program of China under Grant 2018YFE0120200, and Major Scientific and Technological Projects in Henan Province under Grant 191110211500 .

\section{Supplementary Materials}

Figure S1: vertical strain at the top of the subgrade. Figure S2: vertical stress of the cross section. (Supplementary Materials) 


\section{References}

[1] Yue, "Causes and solutions of waves on asphalt road in Wuchang," Available at: http://www.yue366.com/archives/ 3334.html, 2013.

[2] A. Hassani, M. Taghipoor, and M. M. Karimi, "A state of the art of semi-flexible pavements: introduction, design, and performance," Construction and Building Materials, vol. 253, Article ID 119196, 2020.

[3] L. Cheng, Study on Performance and Design Method of Mixture for Semi Flexible Pavement, Master's Thesis, Chang'an University, Xi'an, China, 2002.

[4] Z. Liu, "Application of organic hydraulic composite materials on the highway maintenance," Qinghai Jiaotong Keji, vol. 3, pp. 16-19, 2017.

[5] C. Zhang, S. Jiao, Q. Wu, X. Cao, and W. Zhu, "Study of indoor compaction characteristics and compaction power of $\mathrm{MOH}$ material," Journal of Hefei university of Technology, vol. 40, pp. 938-994, 2017.

[6] H. Wang, Y. Sun, and X. Wei, "Analysis and research on environmental protection benefit of semi-flexible pavement construction of $\mathrm{MOH}$ materials," Energy Conservation \& Environmental Protection in Transportation, vol. 15, pp. 7780, 2019.

[7] Y. Pi, Y. Li, Y. Pi, Z. Huang, and Z. Li, "Strength and micromechanism analysis of cement-emulsified asphalt cold recycled mixture," Materials, vol. 13, pp. 1-18, 2020.

[8] Z. Sun, S. Ma, J. Zhang, and F. Sun, "Microstructure characterisation and performance investigation of a rapid hardening emulsified asphalt seal mixture," Road Materials and Pavement Design, vol. 2020, Article ID 1797856, 16 pages, 2020.

[9] T. Q. Ling, Z. J. Zhao, C. H. Xiong, and Y. Dong, "The application of semi-flexible pavement on heavy traffic roads," International Journal of Pavement Research and Technology, vol. 2, pp. 211-217, 2009.

[10] T. H. M. Le, D.-W. Park, J.-Y. Park, and T. M. Phan, "Evaluation of the effect of fly ash and slag on the properties of cement asphalt mortar," Advances in Materials Science and Engineering, vol. 2019, Article ID 1829328, 10 pages, 2019.

[11] Y. Li, Y. Lyv, L. Fan, and Y. Zhang, "Effects of cement and emulsified asphalt on properties of mastics and $100 \%$ cold recycled asphalt mixtures," Materials, vol. 12, p. 754, 2019.

[12] S. Najjar, A. Mohammadzadeh Moghaddam, A. Sahaf, M. Rasaei Yazdani, and A. Delarami, "Evaluation of the mixed mode (I/II) fracture toughness of cement emulsified asphalt mortar (CRTS-II) using mixture design of experiments," Construction and Building Materials, vol. 225, pp. 812-828, 2019.

[13] Z. Wang, N. Dai, X. Wang, J. Zhang, and H. Guo, "Laboratory investigation on effects of microwave heating on early strength of cement bitumen emulsion mixture," Construction and Building Materials, vol. 236, Article ID 117439, 2020.

[14] W. Zhang, S. Shen, R. D. Goodwin, D. Wang, and J. Zhong, "Performance characterization of semi-flexible composite mixture," Materials, vol. 13, no. 2, p. 342, 2020.

[15] S. Xu, Parameter Design and Simulation on Mixer for $\mathrm{MOH}$ Material with Mixing and Spreading Integrated Machine, Master's Thesis, Chang'an University, Xi'an, China, 2018.

[16] Z. Liu, C. Zhang, and X. Qu, "Study on the parameter optimization and strength mechanism of coal gangue emulsified asphalt mixture," Advances in Materials Science and Engineering, vol. 2020, Article ID 9139575, 12 pages, 2020.
[17] T. Rutherford, Z. Wang, X. Shu, B. Huang, and D. Clarke, "Laboratory investigation into mechanical properties of cement emulsified asphalt mortar," Construction and Building Materials, vol. 65, pp. 76-83, 2014.

[18] M. Gong, Z. Xiong, H. Chen et al., "Evaluation on the cracking resistance of semi-flexible pavement mixture by laboratory research and field validation," Construction and Building Materials, vol. 207, pp. 387-395, 2019.

[19] J. Xiao, W. Jiang, W. Ye, J. Shan, and Z. Wang, "Effect of cement and emulsified asphalt contents on the performance of cement-emulsified asphalt mixture," Construction and Building Materials, vol. 220, pp. 577-586, 2019.

[20] H. Jahanbakhsh, P. Hosseini, F. Moghadas Nejad, and M. Habibi, "Intermediate temperature fracture resistance evaluation of cement emulsified asphalt mortar," Construction and Building Materials, vol. 197, pp. 1-11, 2019.

[21] F. Moghadas Nejad, M. Habibi, P. Hosseini, and H. Jahanbakhsh, "Investigating the mechanical and fatigue properties of sustainable cement emulsified asphalt mortar," Journal of Cleaner Production, vol. 156, pp. 717-728, 2017.

[22] Q. Zhang, S. Dong, H. Chang, and D. Hou, "Consistency properties of emulsified asphalt- cement composite mortar," Journal of Shenyang Jianzhu University Natural Science, vol. 35, pp. 1044-1050, 2019.

[23] X. Xu, H. Gu, Q. Dong, J. Li, S. Jiao, and J. Ren, "Quick heating method of asphalt pavement in hot in-place recycling," Construction and Building Materials, vol. 178, pp. 211-218, 2018.

[24] S. Li, F. Ni, Z. Zhao, Q. Dong, J. Jiang, and Y. Zhao, "Fractal evaluation of the rutting development for multilayer pavement by wheel tracking test," Construction and Building Materials, vol. 222, pp. 706-716, 2019.

[25] M. Hu, J. Zhang, and X. Huang, "Analysis of rutting characteristics of semi-rigid base asphalt pavement," Journal of Highway and Transportation Research and Development, vol. 28, no. 6, pp. 14-18+46, 2011.

[26] X. Hu, S. Zhong, and L. F. Walubita, "Three-dimensional modelling of multilayered asphalt concrete pavement structures: strain responses and permanent deformation," Road Materials and Pavement Design, vol. 16, no. 3, pp. 727-740, 2015.

[27] Y. Jiang, H. Lin, J. Xue, Z. Han, and Z. Chen, "Influences of pavement material and structure on the high-temperature stability of double-layer pavements," Journal of Materials in Civil Engineering, vol. 32, no. 3, Article ID 04020020, 2020.

[28] Y. Jiang, Y. Zhang, C. Deng, Y. Yi, T. Tian, and K. Yuan, "High-temperature rutting resistance of inverted asphalt pavement structure," Advances in Civil Engineering, vol. 2020, Article ID 1937508, 10 pages, 2020.

[29] JTG D50, Specification for Design of Highway Asphalt Pavement, China Communications Publishing \& Media Management Co., Ltd., Beijing, China, 2017.

[30] H. Cao, Mechanical Analysis of Anti-rutting Function for High Modulus Asphalt concrete Pavement, Master's Thesis, Shijiazhuang Tiedao University, Shaoxing, China, 2018.

[31] K. Li, Applicability Study on Semi-flexible Materials as the RutResistance Function Layer of Asphalt Pavement, Doctoral dissertation, South China University of Technology, Guangzhou, China, 2016.

[32] Y. Dong, Study on the Design Parameters and Construction Technology of High-Performance Composite Semi-flexible Pavement, Master's Thesis, Chongqing Jiaotong University, Chongqing, China, 2008. 
[33] G. Liao and X. Huang, Application of ABAQUS Finite Element Software in Road Engineering, Southeast University Press, China, 2014.

[34] X. Zhou, B. Ma, Y. Tian, and X. Wang, "Value of compressive resilient modulus of asphalt mixture in surface layer," Journal of Jiangsu University (Natural Science Edition), vol. 38, pp. 615-620, 2017.

[35] D. Li, The Influence of Different Tire Load and Temperature Field on the Mechanical Performance of Pavement Structure, Master's Thesis, South China University of Technology, Guangzhou, China, 2019.

[36] Y. Wu, X. Jiang, X. Liang, and W. Feng, "Mechanical behavior of typical asphalt pavement structure under wheel loads," Journal of Southwest Jiaotong University, vol. 52, pp. 563-570, 2017.

[37] P. Li, Z. Ding, and W. Rao, "Evaluation of deformation properties of asphalt mixture using aggregate slip test," International Journal of Pavement Engineering, vol. 17, no. 6, pp. 542-549, 2016.

[38] T. D. White, Marshall Procedures for Design and Quality Control of Asphalt Mixtures, Association of Asphalt Paving Technologists Proc., Washington, DC, USA, 1985. 